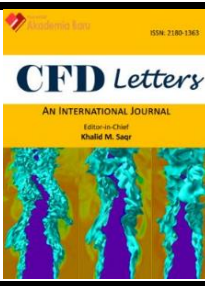

\title{
Mixing Performance of Anchor and Helical Stirrer Blades for Viscous Fluid Applications
}

\author{
Nurul Farhana Mohd Yusof ${ }^{1,}{ }^{*}$, Edmund Ung Eng Soon ${ }^{1}$, Iman Fitri Ismail ${ }^{2}$, Akmal Nizam \\ Mohammed $^{2}$ \\ School of Mechanical Engineering, Universiti Sains Malaysia, 14300 Nibong Tebal, Pulau Pinang, Malaysia \\ Faculty of Mechanical and Manufacturing Engineering, Universiti Tun Hussein Onn Malaysia (UTHM), 86400 Parit Raja, Batu Pahat Johor, \\ Malaysia
}

\section{ARTICLE INFO}

Article history:

Received 22 November 2020

Received in revised form 16 January 2021

Accepted 23 January 2021

Available online 30 January 2021

\section{Keywords:}

Mixing; stirrer blade; oils and grease; CFD

\section{ABSTRACT}

Mixing performance is critical as it may influence the quality of the mixture and operation cost. In a viscous fluid application, the torque required to sustain the high viscosity is very important as it will affect the selection of motor power and cost. The final product of the mixing process is critically influenced by the blade design. The objective of this work is to study the mixing behaviour and the performance of different stirrer blade designs. Two different types of blades were designed and studied to determine how their distinct design features affected flow characteristics in a stirred tank. The liquid viscosity during the formation of grease is taken into account in the determination of viscous force. Fluid flow vector shows that the helical blade efficiently creates a more homogenous uniform mixing. It was found that the helical blade produced $0.25 \mathrm{Nm}$ of torque, whilst the anchor blade produced $0.28 \mathrm{Nm}$ of torque. These values are comparable with the calculation with $8 \%$ error. Therefore, the helical blade can be used as an alternative for the anchor blade due to an efficient mixing process at a faster time and lower power consumption.

\section{Introduction}

In engineering fields, the mixing operation is widely used in polymer, food, paint, water purification, agrochemical product and grease production industries. It is found that the mixing performance is affected by the fluid properties, tank and impeller geometry, rotational speed and the fluid addition process [1]. The final product of the mixing processes is also influenced by the mixing time, type of impeller, number of impeller blades, blade size, working angular speeds, and vessel configurations and the most critical one is the impeller blade design [2]. As the power required for the mixing process decrease, the internal heat generation will also decrease. Therefore, a smaller

\footnotetext{
* Corresponding author.

E-mail address: mefarhana@usm.my (Nurul Farhana Mohd Yusof)
} 
electrical motor, gears and shaft are required for the mixing process, resulting in lower investment and operating costs [3].

Poor mixing performance may result in the formation of dead zones, non-uniform temperature and concentration gradients, which will affect the quality of the final products [4]. Stirrers are used to increase the interaction between the particles and to avoid uneven accumulation at one point [5]. It is more challenging to blend high viscous and complex fluids effectively [6]. The flow in high viscous liquids are more likely in the laminar regime and high power is required to produce turbulent flow [7]. Anchor impellers are widely used for viscous fluid heating or cooling processes to avoid the stagnation of the products at the vessel walls, as the stirrer's blades act as a scraper [8]. Helical ribbon impeller is typically used to enhance the bulk mixing of non-Newtonian fluids in cylindrical vessels to achieve high homogeneity $[9,10]$. Anchors, gates or paddle blades produce circumferential flow and lack of axial flow to sweep through the entire vessel and may cause poor mixing. For helical ribbon impellers, the mixing process started in the region near the blades and the vessel wall where the fluid is subject to high shear strains [4]. The impeller's ability to convert its power input to the fluid flow is referred to as hydraulic efficiency [5], where the higher value represents the higher the energy transferred by the impeller to the agitated material. In this work, the energy efficiency of different impellers for stirring rheologically complex fluids has been investigated. It is found that the new impeller design called Maxblend gives the best performance in terms of power consumption and energy efficiency.

Computational Fluid Dynamic (CFD) has been widely employed as a tool to predict the dynamics flow of mixing operations [11-13]. From numerical simulations, the effects of configurations of mixing tanks and impeller designs can be modelled. Several mixing parameters that have been investigated using numerical methods in CFD include mixing times, power requirements, flow types, and velocity patterns [14]. Since impeller design is the most critical component for determining the performance of mechanically stirred mixers $[2,7]$ several works have been carried out to investigate the effects of impeller type in mixing vessels [15-20]. The mixing performance characteristics of the modified anchor blade [21-24] and helical ribbon blade [25-27] has been evaluated based on the flow characteristics. Most of the existing work is limited to the flow characteristics produced by the impeller blades, whilst the aspect of blade efficiency based on the torque produced by the mixing process is rarely reported. Nevertheless, blade efficiency is important as it will affect the selection of motor power and operation cost. In this study, the CFD technique is used to study the mixing performance of two types of stirrer blades that are typically used in mixing high viscous fluid. The liquid viscosity during the formation of grease is taken into account in the determination of viscous force. The resulting fluid flow and torque required to sustain the high viscosity will be investigated. This will add to the knowledge necessary for choosing the best mixing stirrer blade for a highly viscous fluid, in terms of mixture uniformity at a faster time and lower cost.

\section{Methodology}

\subsection{Mixing System and the Blade Design}

Two types of impeller blades are used in this study; there are anchor and helical blades. These blades are selected as it is most commonly used for mixing of high viscosity solution. The arrangement of the mixing system is shown in Figure 1, which consists of a blade, mixing beaker, stirring rod, base, structure bar, motor and chuck. The dimensions of the anchor and helical blades are shown in Figure 2. The stirrer blades' dimensions are based on the actual dimension of liquid stirring agitator equipment available in the market. 


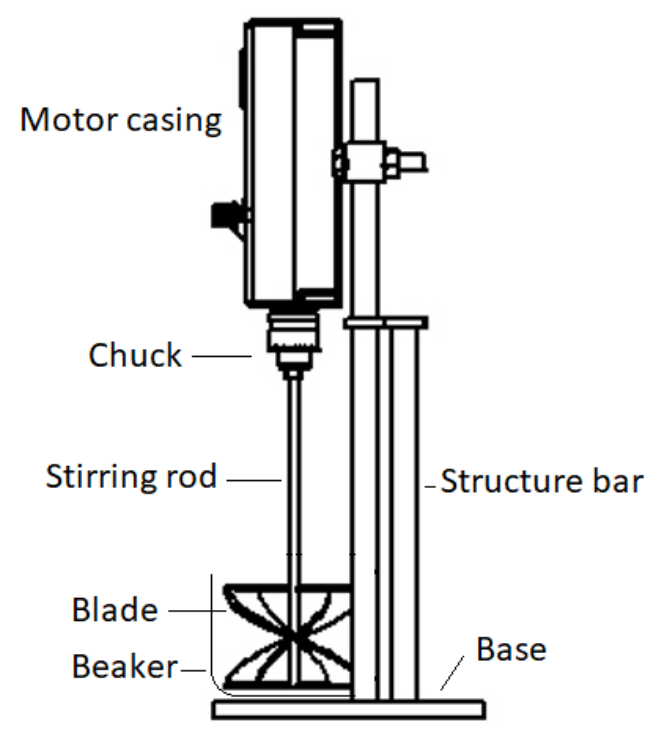

Fig. 1. Mixing stirrer component configuration as used for mixing in the study

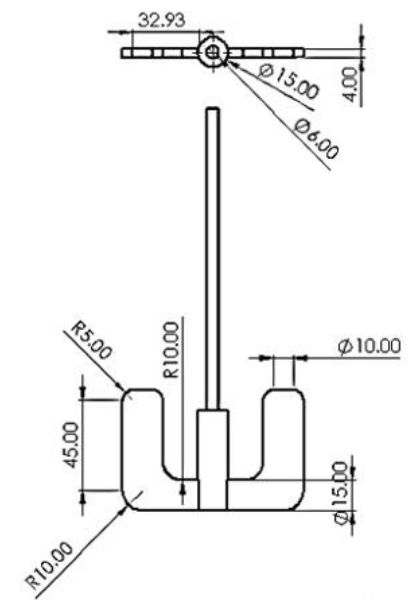

(a)

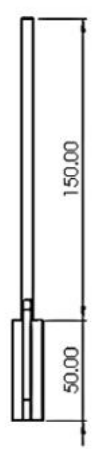

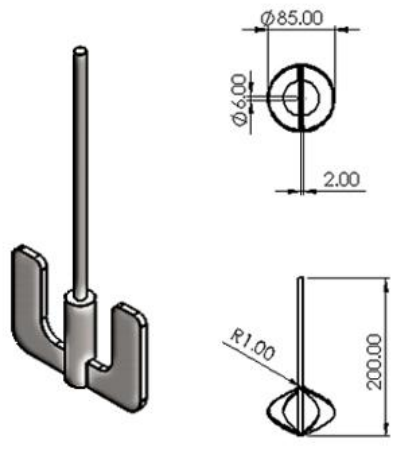

(b)
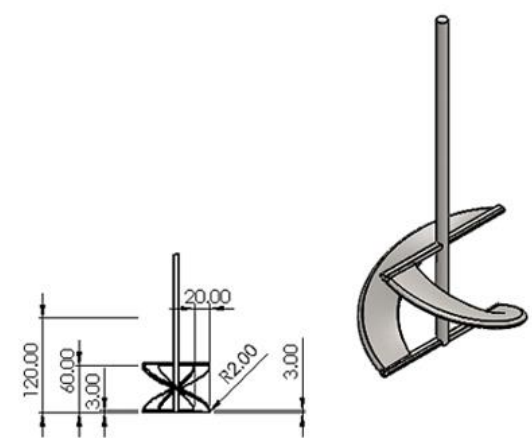

Fig. 2. Dimensions of (a) anchor blade and (b) helical blade of the stirrer equipment

\subsection{Viscous Force}

In the grease base oil mixing process, the fluid viscosity changes from low viscous liquid (base oil) to the high viscous semi-solid grease. The viscous force produced by the base oil and grease during the mixing process is determined based on the grease base oil and beaker characteristic as shown in Table 1. The value is then used to calculate total torque and applied in fluid flow simulation to find a torque response to evaluate the blade performance. The viscous force, $F_{v}$ is determined using Eqs. $(1)-(4)$. The dynamic viscosity is defined as shown in Eq. (1).

$\mu=\frac{\tau}{\Upsilon}$

Where $\tau$ and $\Upsilon$ is shear stress and slope of velocity profile respectively, as shown in Eq. (2) and Eq. (3). 
$\tau=\frac{F}{A}$

$\Upsilon=\frac{v}{h}$

Where $F$ is force, $A$ is the area, $v$ is the velocity and $h$ is the height. Substituting Eq. (3) and Eq. (2) into Eq. (1), the viscous force is computed as shown in Eq. (4):

$$
F_{v}=\frac{A \mu v}{h}
$$

Table 1

Beaker and grease base oil characteristics

\begin{tabular}{ll}
\hline Item & Unit \\
\hline Beaker radius, $\mathrm{r}$ & $0.054 \mathrm{~m}$ \\
Beaker height, $\mathrm{h}$ & $0.1273 \mathrm{~m}$ \\
Beaker volume & $0.001 \mathrm{~m}^{3}$ \\
Beaker cross-section area, A & $0.062 \mathrm{~m}^{2}$ \\
Fluid density, $\rho$ & $1000 \mathrm{~kg} / \mathrm{m}^{3}$ \\
Base oil viscosity $\mu$, at $40^{\circ} \mathrm{C}$ & $0.00011 \mathrm{~m}^{2} / \mathrm{s}$ \\
Angular velocity, $\omega$ & $50 \pi \mathrm{rad} / \mathrm{s}$ \\
Velocity, $v$ & $8.482 \mathrm{~m} / \mathrm{s}$ \\
Viscous force, $\mathrm{F}$ & $0.4544 \mathrm{~N}$ \\
\hline
\end{tabular}

\subsection{Torque Analysis}

Total torque produced by the mixing process using the anchor and helical blades are computed and compared with the simulation to evaluate the blades' performance. The acceleration torque and viscous torque are considered in finding the total torque required for the mixing process. The calculated moment of inertia is then used to find the acceleration torque required by the blades shape for grease mixing. Figure 3 illustrates acceleration torque $T_{\alpha}$ and viscous torque $T_{v}$ produced by the acceleration force $F_{a}$ and viscous force $F_{v}$ during the mixing process.

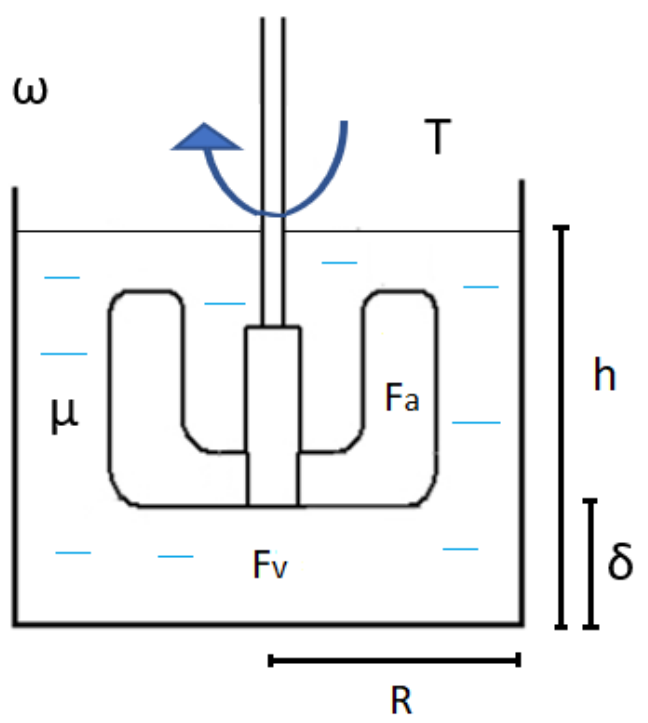

Fig. 3. Viscous force and acceleration force 
For torque calculation, the assumption is the blade rotates at a speed of $1500 \mathrm{rpm}$ and 2 seconds are taken to reach maximum velocity, the angular velocity is obtained at $25 \pi \mathrm{rad} / \mathrm{s}$. Next, the load and mass properties of the chuck, motor and blades are calculated to find the moment of inertia of the system. The assumption for the calculation of the moment inertia of the load is the load produced by NLGI 2 type grease base oil with a viscosity of $960 \mathrm{~kg} / \mathrm{m}^{3}$. This type of grease base oil is considered as it represents the properties of standard grease base oil, as suggested by Ameur et al., [21]. For motor, the calculation is based on the characteristic of stepper motor with a moment of inertia of $0.18-0.56 \mathrm{oz}$ and $1500 \mathrm{rpm}$.

The total moment of inertia is calculated using Eq. (5) and the values are shown in Table 2.

$$
J_{\text {total }}=J_{\text {chuck }}+J_{\text {blade }}+J_{\text {motor }}+J_{\text {load }}
$$

Table 2

Moment of inertia for stirrer blade torque analysis

\begin{tabular}{ll}
\hline Moment of inertia, J & Value $\left(\mathrm{kgm}^{2}\right)$ \\
\hline$J_{\text {chuck }}$ & $1.48 \times 10^{-5}$ \\
$J_{\text {motor }}$ & $1.02 \times 10^{-5}$ \\
$J_{\text {anchor }}$ & $9.86 \times 10^{-5}$ \\
$J_{\text {helix }}$ & $1.13 \times 10^{-4}$ \\
$J_{\text {load }}$ & $2.80 \times 10^{-3}$ \\
$J_{\text {total (anchor) }}$ & $2.79 \times 10^{-3}$ \\
$J_{\text {total(helix) }}$ & $2.94 \times 10^{-3}$ \\
\hline
\end{tabular}

Considering the total torque $\mathrm{T}_{\mathrm{t}}$ is a summation of viscous torque and acceleration torque as shown in Eq. (6).

$T_{t}=T_{\alpha}+T_{v}$

The assumption is that the efficiency of motor, $e=90 \%$ [19]. Then, the acceleration torque is obtained as shown in Eq. (7).

$T_{\alpha}=\frac{J_{\text {total } \alpha}}{e}$

The viscous torque $\mathrm{T}_{\mathrm{v}}$ is determined using Eq. (8).

$T_{v}=\mu \frac{d u}{d y}$

$\frac{d y}{d x}=\frac{v}{\delta}=\frac{r \omega}{\delta}$

Substituting Eq. (9) into Eq. (8), produces Eq. (10).

$T_{v}=\mu \frac{r \omega}{\delta}$

and 


$$
\begin{aligned}
& T_{v}=r \cdot F_{v} \\
& F_{v}=\tau \mathrm{A}
\end{aligned}
$$

Substituting Eq. (12) into Eq. (11), produces Eq. (13).

$T_{v}=r \cdot \tau A$

and

$d T_{v}=r \tau d A$

where $A=\pi r^{2}$

$\frac{d A}{d x}=\frac{d}{d x} 2 \pi r$

When $\mathrm{d} T_{v}=\mathrm{r \tau}(2 \pi \mathrm{rdr})$

$\mathrm{dT}=2 \pi r^{2} \tau d r$

Substituting Eq. (16) into Eq. (15), produces Eq. (17).

$$
\int d T_{v}=\int_{0}^{R} 2 \pi r\left(\mu\left(\frac{r \omega}{\delta}\right) d r\right)
$$

Therefore, viscous torque $T_{v}$ is obtained as shown in Eq. (18).

$T_{v}=\frac{\pi \mu \omega R^{4}}{2 \delta}$

The final torque is shown in Table 3.

\section{Table 3}

Torque calculation of the stirrer

\begin{tabular}{ll}
\hline Torque & Value \\
\hline$T_{\alpha \text { (anchor) }}$ & $0.26 \mathrm{Nm}$ \\
$\mathrm{T}_{\alpha \text { (helix) }}$ & $0.24 \mathrm{Nm}$ \\
$\mathrm{T}_{\mathrm{v}}$ & $1.87 \times 10^{-3} \mathrm{Nm}$ \\
$\mathrm{T}_{\mathrm{t} \text { (anchor) }}$ & $0.26 \mathrm{Nm}$ \\
$\mathrm{T}_{\mathrm{t} \text { (helix) }}$ & $0.24 \mathrm{Nm}$ \\
\hline
\end{tabular}

\subsection{Velocity and Pressure Analysis}

Velocity and pressure analysis are performed to find the velocity vector map of grease mixing when the blade is rotating. The objective is to find the total torque produced by the blades and grease during mixing by simulation and the value is compared with a theoretical calculation. Torque value indicates the blade design's power consumption and can be used to indicate the blade design 
performance. The torque response of the mixer can be defined as the mass resistance to mixing and for the case of the same fluid, larger designs can be expected to exhibit higher resistance. This will result in a higher torque response due to the increase in the surface area normal to the direction of motion of the anchor [7]. This value can help in the selection of a suitable motor with maximum torque required for the successful mixing process. Motor torque is very critical for the blade to face the change in viscosity. From the analysis, we can also see the convection current that the blade provides, thus determining which blade has better mixing potential and lesser torque needed for mixing [22]. Figure 4 shows the setup of the fluid flow simulation where the blade is set to rotate clockwise. A beaker size of $1 \mathrm{~L}$ is used. The fluid density is set between a range of oil to grease as the function of the blade is to mix the liquid oil to semi-solid grease. Simulation settings for velocity and pressure analysis are shown in Table 4.

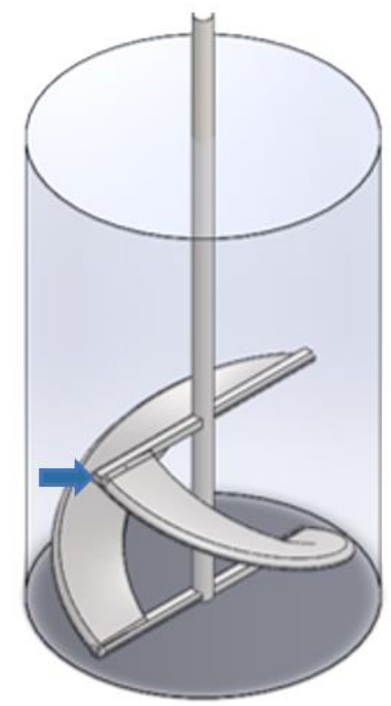

(a)

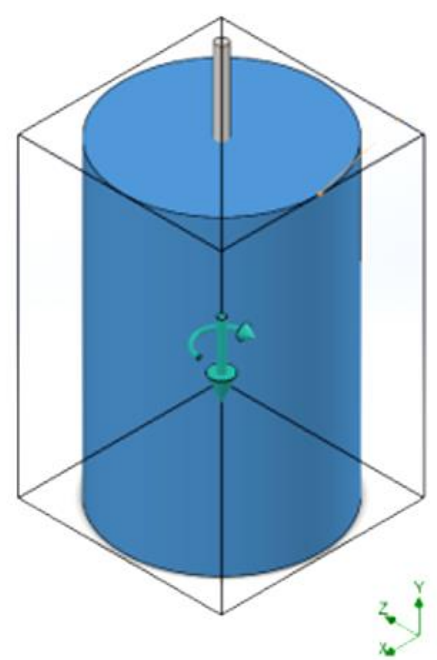

(b)

Fig. 4. Flow simulation setup for (a) Viscous force and (b) Rotation of the stirrer

Table 4

Settings for velocity and pressure simulation

\begin{tabular}{ll}
\hline Parameter & Set Value \\
\hline Analysis Type & Internal Flow \\
Governing Equations & $\begin{array}{l}\text { Conservation of mass, momentum } \\
\text { and energy } \\
\text { k- } \varepsilon \text { model }\end{array}$ \\
Turbulence Model & $-9.81 \mathrm{~m} / \mathrm{s}^{2}$ in Y axis \\
Gravity & Non-newtonian oil as in Table 1 \\
Fluid & $101,325 \mathrm{~Pa}$ \\
Initial Pressure & $50 \mathrm{rad} / \mathrm{s}$ around Y-axis \\
Blade Rotational Speed &
\end{tabular}

\section{Numerical Simulation}

The simulation is performed by using SolidWorks 2019 which is based on the finite element method to solve flow equations. The RRF (Rotating Reference Frame) approach is used where a cylinder is used as a reference frame which represents the walls of a typical dimension of a 1 litre beaker. The stirrer blade is kept stationary and the rotating frame (the cylindrical wall that represents 
the beaker) is given an angular velocity. This technique has been used by other researchers [5, 27] for various mixing systems and accurate results were obtained. The meshing is performed using a global average element size where the suggested value based on the model volume and surface area is applied. Simulations were run in a platform with Ryzen 5 CPU $3.00 \mathrm{GHz}$ with $16 \mathrm{~GB}$ of RAM. The transient simulation was set to 435 iterations per time step with a residual target of $1 \times 10^{-05}$.

Grid Independence Test (GIT) is carried out in order to ensure that the results are not influenced by the grid size. Figure 5 shows the GIT for the geometry used in this study. From the graph, it is observed that the simulated value of torque varies with cell count until 70000 cells. After that, the simulated torque maintains at $0.05 \mathrm{Nm}$. On the other hand, the CPU simulation time increases with the increases of total cell count. This shows that higher cell count will result in longer simulation time. Therefore, subsequent simulation runs utilize no less than 70000 cells to ensure grid independence is maintained as shown in Table 5.

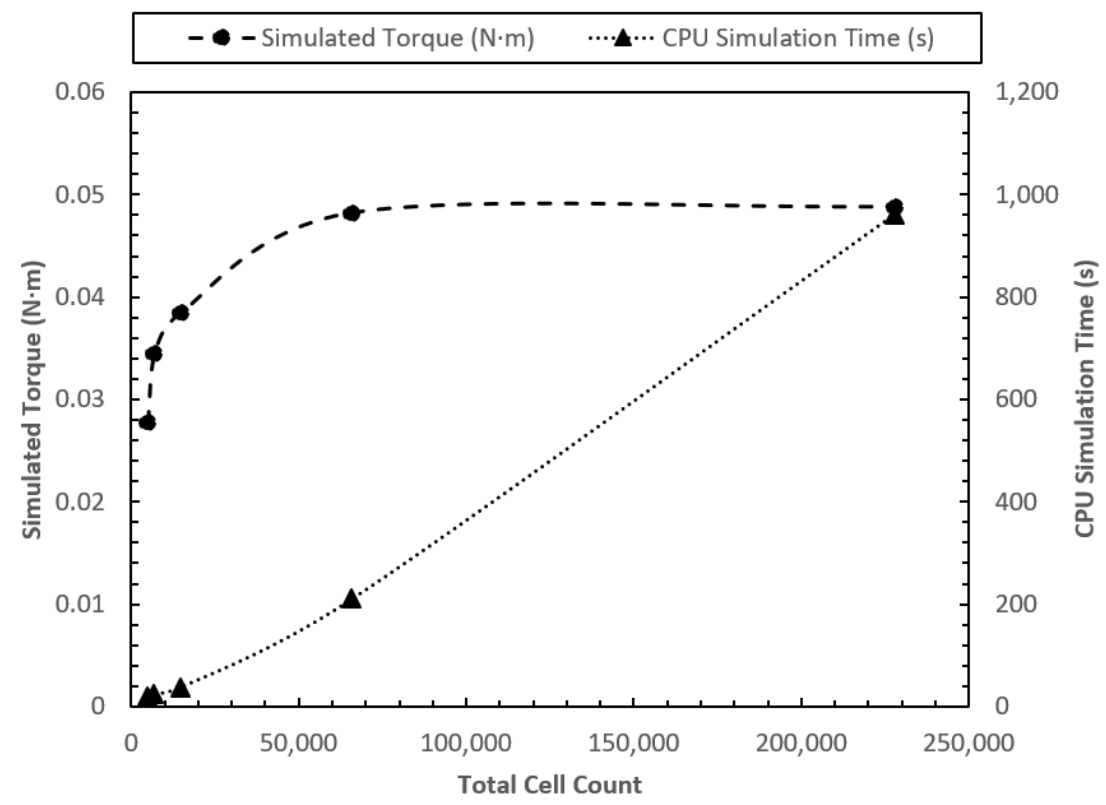

Fig. 5. Grid Independence Test

Table 5

Grid Independence Test data

\begin{tabular}{lllll}
\hline Study & $\begin{array}{l}\text { Mesh Size } \\
(\mathrm{mm})\end{array}$ & Cell Count & $\begin{array}{l}\text { Torque } \\
(\mathrm{N} \cdot \mathrm{m})\end{array}$ & $\begin{array}{l}\text { CPU Time } \\
(\mathrm{s})\end{array}$ \\
\hline 1 & 20 & 4891 & 0.028 & 19 \\
2 & 15 & 6917 & 0.034 & 25 \\
3 & 10 & 14634 & 0.038 & 38 \\
4 & 5 & 65898 & 0.048 & 211 \\
5 & 2 & 228016 & 0.048 & 962 \\
\hline
\end{tabular}

\section{Results}

\subsection{Velocity Distribution}

The velocity vector map of the anchor impeller is shown in Figure 6. From the front view of the blade in Figure 6(a), it is observed that the blade rotation causes a liquid flow to the centre region and cause the fluid velocity to rise and become higher. From the isometric view in Figure 6(b), it is shown that the blades drove the fluid to the walls at high viscosity of 1.469 , which then splashed back in opposite directions towards the impeller rod. There was more turbulence experienced at the space 
between rod and blade, due to the presence of holes. This type of impeller was not very efficient in distributing the fluid all over the beaker as the fluid mixing only occurs in the centre region. The generated flow is expected to cause higher concentrations of the solution in the lower region of the beaker compared to the upper regions. Validation with existing work shows a good agreement where the higher turbulence occurs at the anchor blade surface [17]. However, the velocity vector at the other different areas in the mixing tank is different due to different liquid viscosity.

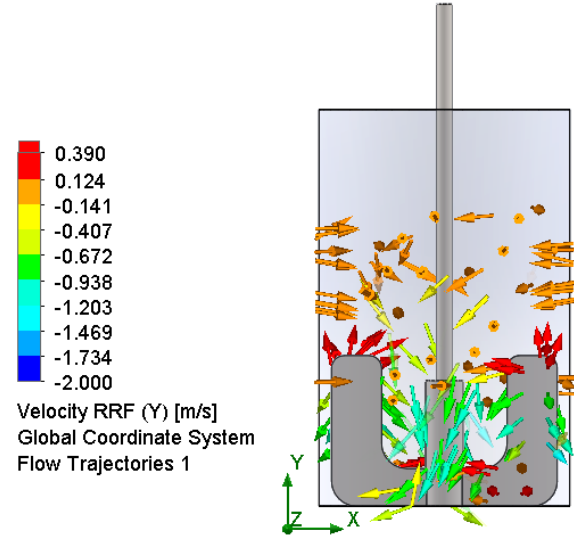

(a)

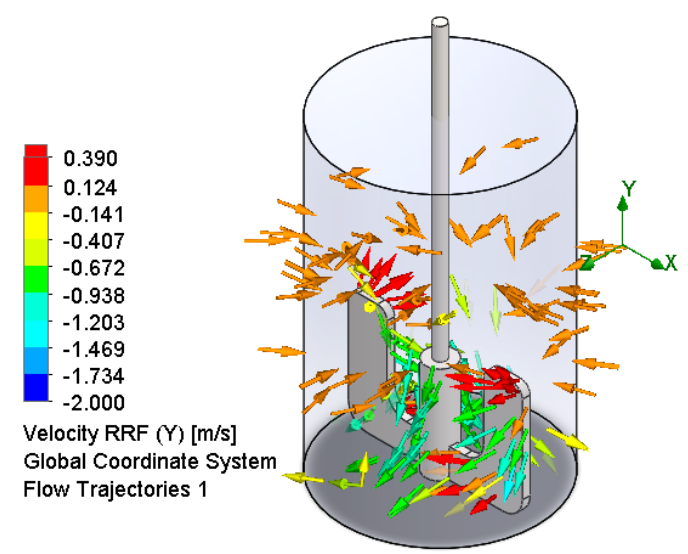

(b)

Fig. 6. Velocity vector map of anchor blade (a) front view (b) isometric view

Figure $7(a)$ represents the frontal view of the helical blade. The figures show that the geometry of the blade drives the liquid to the lower region at high speed. Isometric view in Figure $7(\mathrm{~b})$ shows that the liquid flows back to the upper region, consequently repeat the same process. The fluid is well projected vertically and horizontally in both directions. This shows that the helical blade design was able to distribute the fluid towards the lower and upper region of the beaker efficiently. This is due to the curves present in helical blade design that allow for the axial and counter flow of fluid during mixing. The velocity streamlines are observed to have dispersed to all regions of the beaker. This shows that this type of impeller can efficiently distribute the particles and create a more homogenous solution. According to Cokljat et al., [15] helical impellers are designed to enhance especially the liquid's axial movement for the process of replacement of liquids that is needed for the mixing of high viscosity materials. The flows generated is expected will increase turbulence and mixing performance.

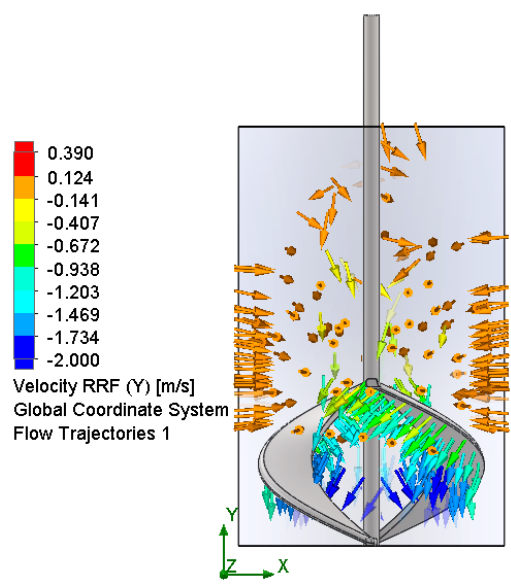

(a)

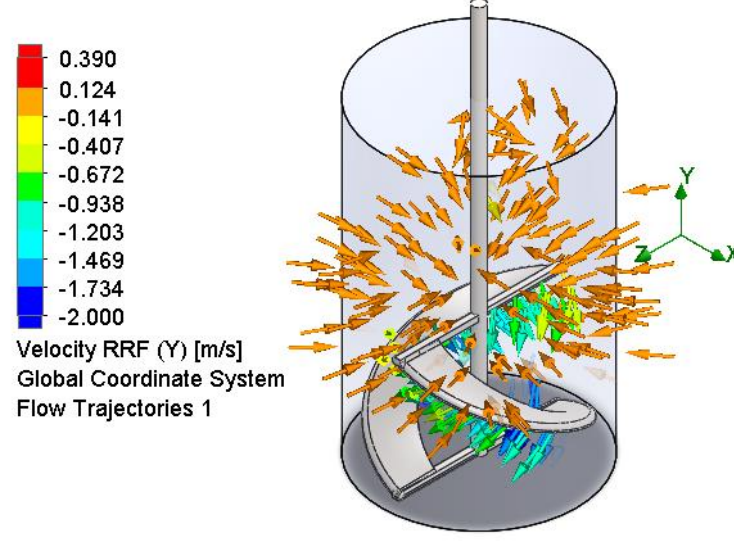

(b)

Fig. 7. Velocity vector map of helix blade (a) front view (b) isometric view 


\subsection{Pressure Distribution}

Figure 8 shows the pressure vector map for anchor blade from (a) front view and (b) isometric view. It is observed that high pressure formed at the blade surface as it need to shelter the viscous force produced by the high viscosity grease. The pressure difference between blade surface and central region forces the fluid to flow at high velocity to the central region of the beaker and allows for the mixing process.

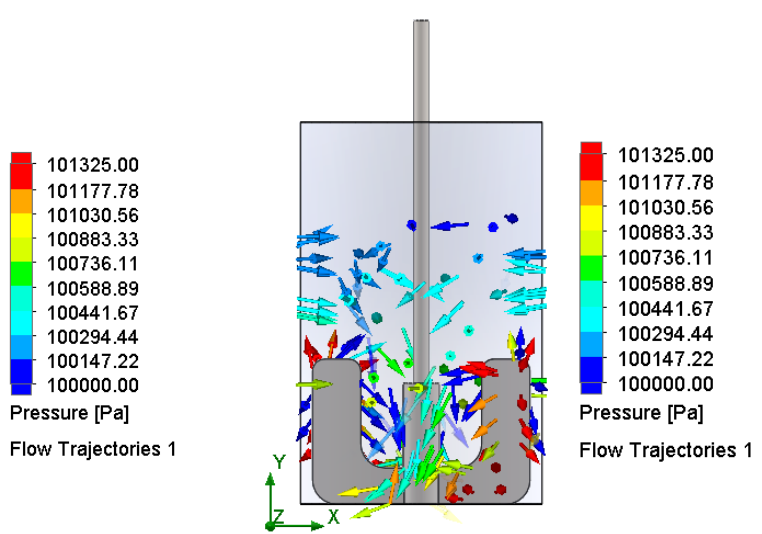

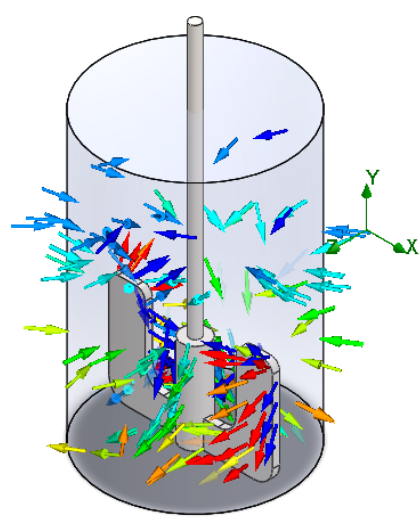

(b)

Fig. 8. Pressure vector map of anchor blade (a) front view (b) isometric view

Figure 9(a) shows the pressure vector map for helical blade impeller. It is observed that high pressure only occurs at the edge of the blade, then almost uniformly distributed in other regions in the beaker results in lower average pressure compared to the anchor blade. The high-pressure difference between the upper region of the blade and centre region in the beaker forces the fluid to flow downward. The isometric view in Figure 9(b) exhibits different pressure distributions at the blade edges, centre region and beaker surface wall, thus create a high turbulence flow and boost the fluid to flow to all areas for uniform mixing. From the figures, it is observed that the convection current is more apparent compared to the anchor blade. This type of impeller was expected to distribute the fluid more evenly throughout the entire volume [4]. From the obtained results, it was evident that the helical blade impeller types exhibited better-mixing results, which is essential in achieving concentration homogeneity in the production of high viscosity grease. The helical blade also takes up lesser time for even mixing which can be more efficient compared to the anchor blade.

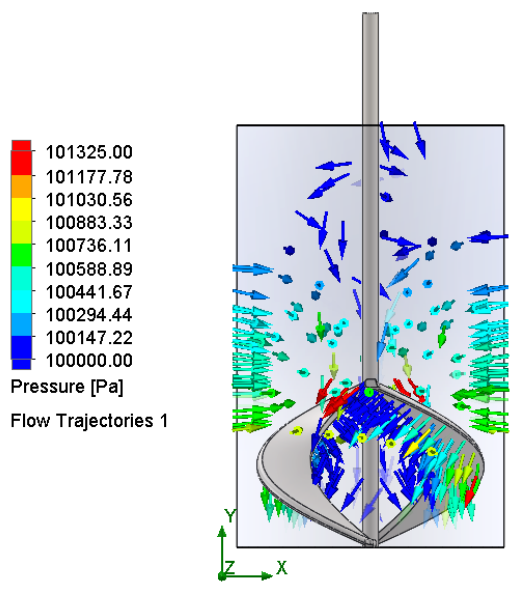

(a)

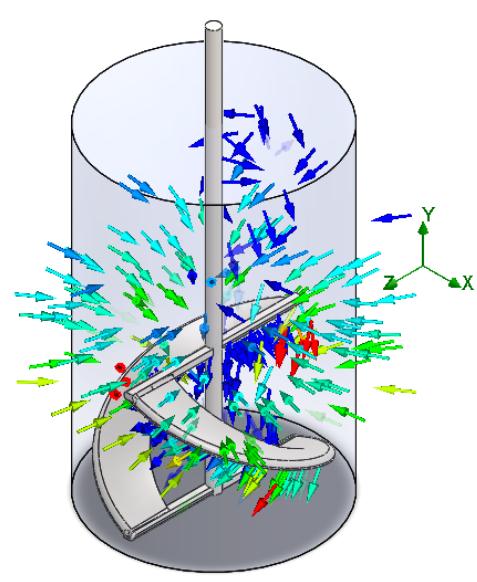

(b)

Fig. 9. Pressure vector map of helical blade (a) front view (b) isometric view 


\subsection{Torque Response}

The torque response of the anchor blade is presented in Figure 10. The starting torque is normally high before its working in optimal stable condition. The torque value is $1.7 \mathrm{Nm}$ when the impeller started the stirring process and finally stabilize at $0.28 \mathrm{Nm}$.

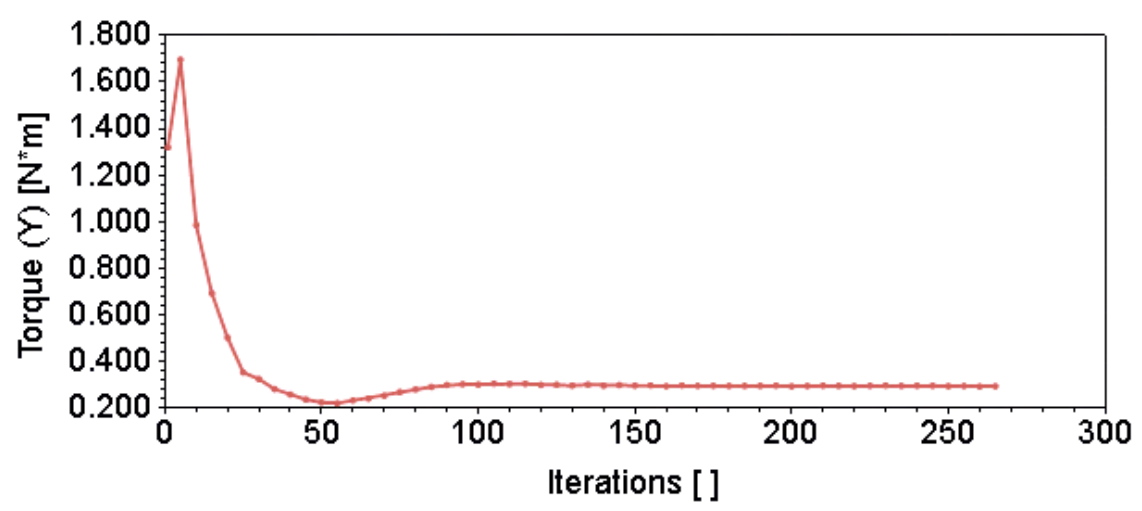

Fig. 10. Torque response of anchor blade

For the helical blade, the torque response started at a relatively lower value than anchor blade which is at $0.9 \mathrm{Nm}$. After that, the torque response reduces to the stable operating value at $0.25 \mathrm{Nm}$. This is expected due to the wider blade surface area compared to the anchor blade. Furthermore, as seen in the pressure distribution of the helix blade in Figure 11, the pressure distributed throughout the beaker efficiently at lower pressure. Therefore, lesser force is required for a stirring, subsequently, reduce the energy consumption in the mixing process. The torque values are comparable with the calculation with $8 \%$ error.

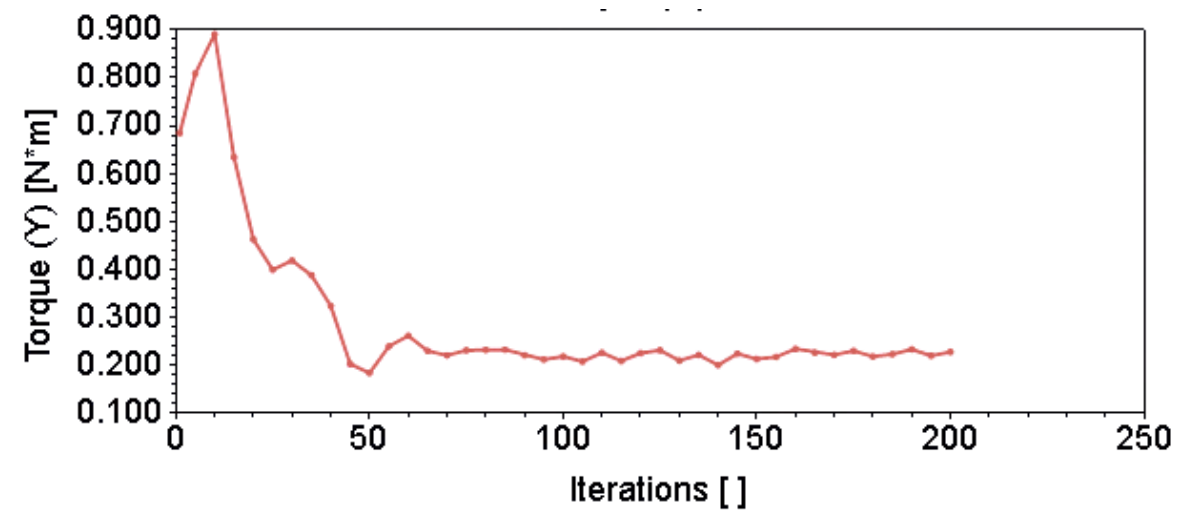

Fig. 11. Torque response of helical blade

The finding is validated with experimental work by Liu et al., [28] as shown in Figure 12 and the accompanying Table 6 . The figure compares the power number ( $\mathrm{Np}$ ) versus the Reynolds number (Re) for the two simulated blades used in this study against the three types of blades tested in experiments. In the experimental study, the three blade types were named as large double blade (LDB), full zone (FZ), and impeller double helicon ribbon (DHR) impeller blades respectively. From the figure, the result for anchor blade simulation matches closely with the LDB and FZ blade torques, whilst the helical blade result lies within an acceptable range as compared to the DHR torque values. The finding shows that the helical blade can be used as an alternative for the anchor blade due to an efficient mixing process at lower power consumption. 


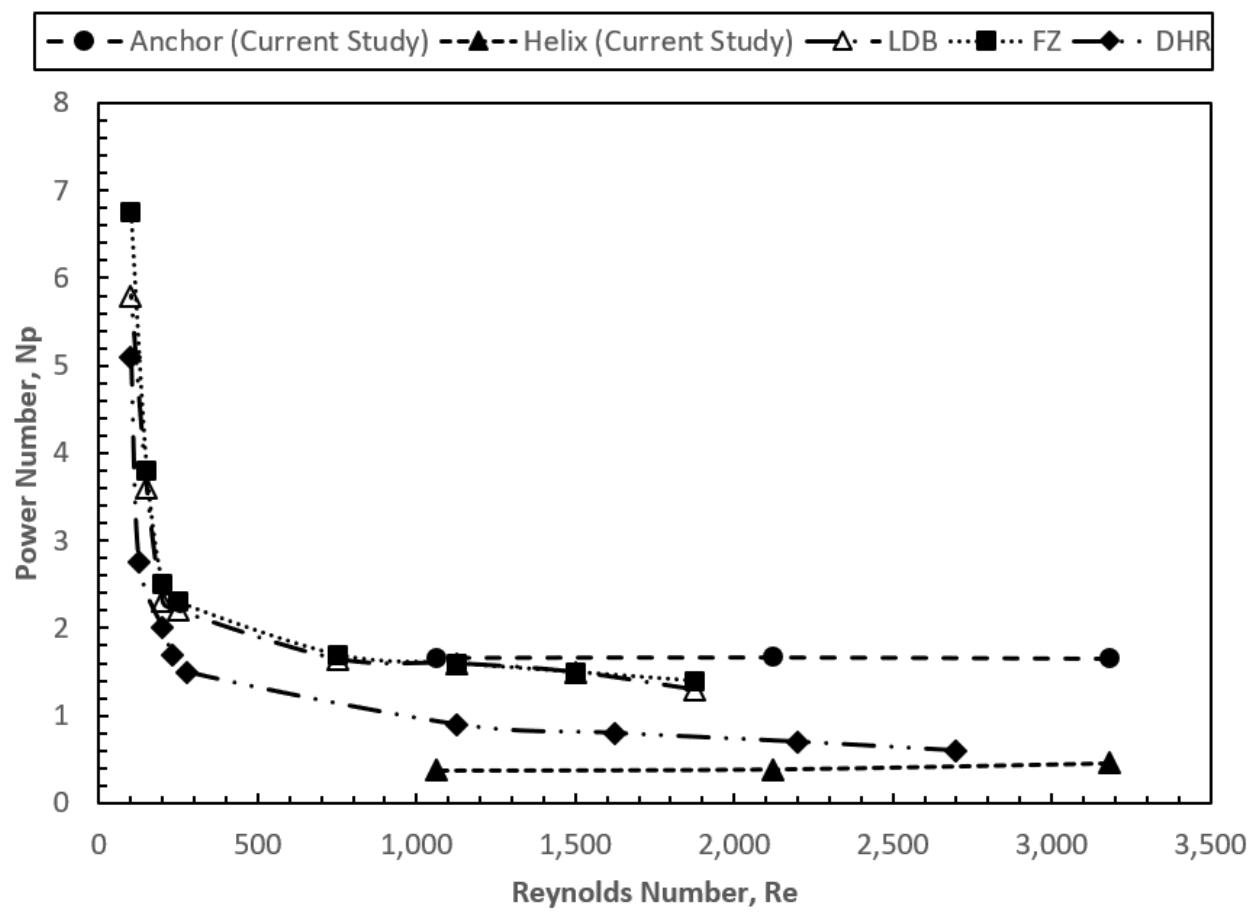

Fig. 12. Validation of current study compared to experimental data

Table 6

Validation of current study against experimental data from Liu et al., [28]

\begin{tabular}{|c|c|c|c|c|c|}
\hline \multirow{3}{*}{$\begin{array}{l}\text { Reynolds } \\
\text { Number }\end{array}$} & \multicolumn{5}{|c|}{ Power Number } \\
\hline & \multicolumn{2}{|c|}{ Current Study } & \multicolumn{3}{|c|}{ Liu et al., (2015) } \\
\hline & Anchor & Helix & LDB & FZ & DHR \\
\hline 100 & & & 5.80 & 6.75 & 5.10 \\
\hline 125 & & & & & 2.75 \\
\hline 150 & & & 3.60 & 3.80 & \\
\hline 200 & & & 2.30 & 2.50 & 2.00 \\
\hline 230 & & & & & 1.70 \\
\hline 250 & & & 2.20 & 2.30 & \\
\hline 275 & & & & & 1.50 \\
\hline 750 & & & 1.65 & 1.70 & \\
\hline 1060 & 1.67 & 0.37 & & & \\
\hline 1125 & & & 1.60 & 1.60 & 0.90 \\
\hline 1500 & & & 1.50 & 1.50 & \\
\hline 1625 & & & & & 0.80 \\
\hline 1875 & & & 1.30 & 1.40 & \\
\hline 2120 & 1.67 & 0.38 & & & \\
\hline 2200 & & & & & 0.70 \\
\hline 2700 & & & & & 0.60 \\
\hline 3181 & 1.65 & 0.46 & & & \\
\hline
\end{tabular}

\section{Conclusions}

The mixing performance of stirrer blades for viscous fluid applications has been presented in this study. Helical blades design causes a pressure difference between the upper region of the blade and centre region of the beaker then forces the fluid to flow to all areas. The resulting fluid flow efficiently creates a more homogenous and uniform mixing. The torque response from the mixing process is 
$0.28 \mathrm{Nm}$ and $0.25 \mathrm{Nm}$ for anchor and helical blade respectively. The values are comparable with the calculation with $8 \%$ error. The finding shows that the helical blade can be used as an alternative for the anchor blade due to an efficient mixing process at a faster time and lower power consumption.

\section{Acknowledgement}

This research was funded by a grant from the Ministry of Higher Education of Malaysia (FRGS/1/2019/TK03/USM/03/4).

\section{References}

[1] Zhang, Pan, Guanghui Chen, Jihai Duan, and Weiwen Wang. "Mixing characteristics in a vessel equipped with cylindrical stirrer." Results in Physics 10 (2018): 699-705.

https://doi.org/10.1016/i.rinp.2018.07.024

[2] Isabela, M.P., and Leandro, S.O. "CFD Modelling and Simulation of Transesterification Reactions of Vegetable Oils With an Alcohol in Baffled Stirred Tank Reactor." Applied Mechanics and Materials 390 (2013): 86-90. https://doi.org/10.4028/www.scientific.net/AMM.390.86

[3] Jaszczur, Marek, Anna Młynarczykowska, and Luana Demurtas. "Effect of Impeller Design on Power Characteristics and Newtonian Fluids Mixing Efficiency in a Mechanically Agitated Vessel at Low Reynolds Numbers." Energies 13, no. 3 (2020): 640.

https://doi.org/10.3390/en13030640

[4] Tsui, Yeng-Yung, and Yu-Chang Hu. "Flow characteristics in mixers agitated by helical ribbon blade impeller." Engineering Applications of Computational Fluid Mechanics 5, no. 3 (2011): 416-429. https://doi.org/10.1080/19942060.2011.11015383

[5] Ameur, Houari. "Energy efficiency of different impellers in stirred tank reactors." Energy 93 (2015): 1980-1988. https://doi.org/10.1016/i.energy.2015.10.084

[6] Tsz-Chung Mak, A. "Solid-liquid mixing in mechanically agitated vessels." PhD. University of London (1992).

[7] Ameur, Houari. "Effect of some parameters on the performance of anchor impellers for stirring shear-thinning fluids in a cylindrical vessel." Journal of Hydrodynamics 28, no. 4 (2016): 669-675. https://doi.org/10.1016/S1001-6058(16)60671-6

[8] Ge, Chun-Yan, Jia-Jun Wang, Xue-Ping Gu, and Lian-Fang Feng. "CFD simulation and PIV measurement of the flow field generated by modified pitched blade turbine impellers." Chemical Engineering Research and Design 92, no. 6 (2014): 1027-1036. https://doi.org/10.1016/i.cherd.2013.08.024

[9] Peixoto, S. M. C., J. R. Nunhez, and C. G. Duarte. "Characterizing the flow of stirred vessels with anchor type impellers." Brazilian Journal of Chemical Engineering 17, no. 4-7 (2000): 925-936. https://doi.org/10.1590/S0104-66322000000400057

[10] Gijón-Arreortúa, Ixchel, and Alberto Tecante. "Mixing time and power consumption during blending of cohesive food powders with a horizontal helical double-ribbon impeller." Journal of Food Engineering 149 (2015): 144-152. https://doi.org/10.1016/i.jfoodeng.2014.10.013

[11] Mustafa, Adnan Ghulam, Mohd Fadhil Majnis, and Nor Azyati Abdul Muttalib. "CFD Study on Impeller Effect on Mixing in Miniature Stirred Tank Reactor." CFD Letters 12, no. 10 (2020): 15-26.

https://doi.org/10.37934/cfdl.12.10.1526

[12] Liang, Chua Bing, Akmal Nizam Mohammed, Azwan Sapit, Mohd Azahari Razali, Mohd Faisal Hushim, Amir Khalid, and Nurul Farhana Mohd Yusof. "Numerical Simulation of Aerofoil with Flow Injection at the Upper Surface." CFD Letters 12, no. 1 (2020): 98-110.

[13] ZHANG, Minge, Lühong ZHANG, Bin Jiang, Y. I. N. Yuguo, and L. I. Xingang. "Calculation of metzner constant for double helical ribbon impeller by computational fluid dynamic method." Chinese Journal of Chemical Engineering 16, no. 5 (2008): 686-692. https://doi.org/10.1016/S1004-9541(08)60141-X

[14] Pakzad, Leila, Farhad Ein-Mozaffari, and Philip Chan. "Using electrical resistance tomography and computational fluid dynamics modeling to study the formation of cavern in the mixing of pseudoplastic fluids possessing yield stress." Chemical Engineering Science 63, no. 9 (2008): 2508-2522. https://doi.org/10.1016/i.cep.2007.12.003

[15] Cokljat, D., M. Slack, and S. A. Vasquez. "Progress in Comp." Fluid Dyn 6 (2006): 168-178. https://doi.org/10.1504/PCFD.2006.009494 
[16] Khopkar, A. R., G. R. Kasat, A. B. Pandit, and V. V. Ranade. "Computational fluid dynamics simulation of the solid suspension in a stirred slurry reactor." Industrial \& engineering chemistry research 45, no. 12 (2006): 4416-4428. https://doi.org/10.1021/ie050941q

[17] Zalc, J. M., E. S. Szalai, M. M. Alvarez, and F. J. Muzzio. "Using CFD to understand chaotic mixing in laminar stirred tanks." AlChE Journal 48, no. 10 (2002): 2124-2134. https://doi.org/10.1002/aic.690481004

[18] Tatterson, Gary B. Scaleup and design of industrial mixing processes. New York: McGraw-Hill, 1994.

[19] Torotwa, lan, and Changying Ji. "A study of the mixing performance of different impeller designs in stirred vessels using computational fluid dynamics." Designs 2, no. 1 (2018): 10. https://doi.org/10.3390/designs2010010

[20] Adanta, Dendy, Warjito Budiarso, Ahmad Indra Siswantara, and Aji Putro Prakoso. "Performance comparison of NACA 6509 and 6712 on pico hydro type cross-flow turbine by numerical method." Journal of Advanced Research in Fluid Mechanics and Thermal Sciences 45, no. 1 (2018): 116-127.

[21] Ameur, Houari, and Abdellah Ghenaim. "Mixing of complex fluids in a cylindrical tank by a modified anchor impeller." ChemistrySelect 3, no. 26 (2018): 7472-7477. https://doi.org/10.1002/slct.201801047

[22] Kamla, Youcef, Houari Ameur, Abdelkader Karas, and Mohammed Ilies Arab. "Performance of new designed anchor impellers in stirred tanks." Chemical Papers 74, no. 3 (2020): 779-785. https://doi.org/10.1007/s11696-019-00902-x

[23] Ameur, Houari, and Youcef Kamla. "Geometrical modifications of the anchor impeller to enhance the overall performances in stirred tanks." Instal 6 (2020): 42-45. https://doi.10.36119/15.2020.6.5

[24] Ameur, Houari, Youcef Kamla, Abdessalam Hadjeb, Ilies Mohammed Arab, and Djamel Sahel. "Data on mixing of viscous fluids by helical screw impellers in cylindrical vessels." Data in brief 8 (2016): 220-224. https://doi.org/10.1016/i.dib.2016.05.036

[25] Ameur, Houari, Youcef Kamla, and Djamel Sahel. "Performance of helical screw impellers for mixing of viscous liquids in cylindrical reactors." ChemistrySelect 2, no. 5 (2017): 1891-1894. https://doi.org/10.1002/slct.201602072

[26] Hadjeb, Abdessalam, Mohamed Bouzit, Youcef Kamla, and Houari Ameur. "A new geometrical model for mixing of highly viscous fluids by combining two-blade and helical screw agitators." Polish Journal of Chemical Technology 19, no. 3 (2017): 83-91. https://doi.org/10.1515/pjct-2017-0053

[27] Aubin, Joelle, Isabelle Naude, Joël Bertrand, and Catherine Xuereb. "Blending of Newtonian and shear-thinning fluids in a tank stirred with a helical screw agitator." Chemical Engineering Research and Design 7, no. 8 (2000): 1105-1114. https://doi.org/10.1205/026387600528382

[28] Liu, Baoqing, Manman Wang, Jingliang Liu, Luyan Qian, and Zhijiang Jin. "Experimental study on micromixing characteristics of novel large-double-blade impeller." Chemical Engineering Science 123 (2015): 641-647. https://doi.org/10.1016/j.ces.2014.11.056 